September 2012 issue of Wilderness \& Environmental Medicine. I was not surprised to see the topic raised owing to the safety concerns about climbers going beyond their limits, trusting to the efficacy of the agents well known to treat high altitude illness once it occurs. One only has to read Anatoli Boukreev's concerns about Scott Fischer using acetazolamide (Diamox) to make up for his lack of acclimatization before his fatal Everest attempt to realize the gravity of having too much confidence in the benefits of medication. However, as a 60-year-old sea-level dweller who beat himself into shape over 9 months in preparation for the wilderness medicine trek to Everest Base Camp with Dr Robert (Brownie) Schoene in 2010, I defend my decision to bring and use everything I thought would help me achieve my goal of reaching base camp and the summit of Kala Patar. I walked out of a large outdoor clothing retailer in Chicago with $\$ 600$ of cold-weather gear including $\$ 25$ nonchafing boxers. I talked to the boot department manager at another outdoor clothing store in Freeport, Maine to choose the boots for the trek. I also loaded up on acetazolamide, dexamethasone (Decadron), ciprofloxacin (Cipro), caffeine tablets (No-Doz), and loperamide (Imodium) for the journey.

Like most of my trek teammates, I eschewed the use of dexamethasone and acetazolamide until 2 of the team members, who were smiling in photos taken on the trail 18 hours before, experienced acute mountain sickness in Dingboche, Nepal, and were in danger of being left behind. I did not hesitate to retreat to my room to start my medications to avoid the same fate. The trek in the Himalayas was a watershed event in my life. Since my return, I have studied Buddhism, attempted to learn the Sherpa language, and kept up my physical training. I have lectured on my experience to our hospital staff. I would hate to think that I might have had to give up along the trail because I took a stubbornly purist attitude against stacking the deck against failure by using the medications that I have been learning about for years. I am now preparing for a return to Everest Base Camp with the Wilderness Medicine Society this spring, and I will go armed with better choices in medications as a result of the knowledge gained on my first trip.

Patrick Mulroy, MD

Bay Pines Veterans Administration Healthcare System Bay Pines, FL

\section{“Performance Enhancing” Drugs at High Altitude}

\section{To the Editor:}

We read with interest the editorial: "Medical and sporting ethics of high altitude mountaineering" 1 and the thoughtful comments of the invited discussants. ${ }^{2} \mathrm{We}$ would like to clear up what we believe are a few misconceptions.

It is debatable whether the use of performanceenhancing drugs in high-altitude mountaineering is increasing as a percentage of people taking part in the sport. We remember the popularity of "triple-D's:" Diamox (acetazolamide), dexamethasone and Dexedrine (dextroamphetamine) in certain circles several decades ago, but that was hardly the beginning. Caffeine tablets were carried by British expeditions on Mt. Everest in the 1920s. There certainly seem to be many physicians nowadays who are clueless about high altitude mountaineering yet who are willing to prescribe drugs for prevention of high altitude illness ${ }^{3}$ and perhaps also to enhance performance at altitude. Many drugs are also purchased over the counter in pharmacies in unregulated countries based on misinformation available on the Internet.

We do not believe that the World Anti-Doping Agency (WADA) and its 2012 Prohibited List ${ }^{4}$ is relevant to this discussion. "Doping" applies only to the use of drugs or other means to confer an advantage in competition. High altitude mountaineering may be competitive, but it is not a formal regulated competition. No official body, including the International Mountaineering and Climbing Federation (UIAA), decides whether ascents "count." Any WADA type regulation would be unenforceable. Acetazolamide is included on the WADA list of prohibited substances in the category of "Diuretics and other masking agents," because diuretics enhance the excretion of banned substances, making them harder to detect. The document does not specifically mention dexamethasone, but says, "All glucocorticosteroids are prohibited ..."

Although many substances banned by WADA, such as anabolic steroids, are inherently harmful, acetazolamide and dexamethasone have legitimate uses in the prevention and treatment of high altitude illness. ${ }^{5}$ Most experts agree that drugs should not be used as a substitute for gradual acclimatization except under extreme circumstances such as a rescue attempt. The use of acetazolamide to aid acclimatization is widely accepted. ${ }^{5}$ There is no ethical dilemma for prescribing physicians, as long as they are aware of the risks and potential benefits of these drugs.

There have never been special mountaineering ethics, although there have been heated arguments about style. In the $19^{\text {th }}$ Century, long before Reinhold Messner declared that he would climb Mt Everest "by fair means or not at all," the famous British mountaineer, Albert Mummery joked that an alpine peak, the Dent du Géant, was: "Absolutely inaccessible by fair means." There has never 
been an accepted definition of "fair means." This will always be in the eye of the beholder. We would encourage one ethical principle: to tell the truth by disclosing the use of supplemental oxygen and other drugs in reporting ascents, just as one would admit to using bolts or fixed ropes.

Climbers should make their own informed decisions, with the help of knowledgeable medical advisors, about the use of oxygen and other legal drugs such as acetazolamide and dexamethasone. Nobody can forbid the use of these drugs and other "artificial aids" outside of officially regulated competition. We agree with Dr. Basnyat that "adults will ultimately make their own choices." 2

Ken Zafren, MD

Department of Emergency Medicine, Alaska Native Medical Center, Anchorage, AK, USA

Division of Emergency Medicine, Stanford University Medical Center, Palo Alto, CA, USA

Himalayan Rescue Association, Kathmandu, Nepal International Commission for Mountain Emergency Medicine (ICAR MEDCOM)

Franz Berghold, Dr med Salzburg, Austria Department of Sports Sciences, University of Salzburg, Austria Austrian Society of Mountain and High Altitude Medicine (ÖGAHM) Medical Commission of the International Mountaineering and Climbing Federation (UIAA MEDCOM)

David Hillebrandt, MB BS General Practitioner, Devon, England, UK Hon. Medical Advisor to the British Mountaineering Club Medical Commission of the International Mountaineering and Climbing Federation

(UIAA MEDCOM)

\section{References}

1. Wagner DR. Medical and sporting ethics of high altitude mountaineering: the use of drugs and supplemental oxygen. Wilderness Environ Med. 2012;23:205-206.

2. Cushing TA, McIntosh SE, Keyes LE, et al. Performanceenhancing drugs-commentaries. Wilderness Environ Med. 2012;23:207-211.

3. Subedi D, Marahatta R, Sharma S, Bajracharya R, Hillenbrand P, Soon Y. Trekkers' awareness of acute mountain sickness and acetazolamide. Wilderness Environ Med. 2008; 19:321-322.
4. World Anti-Doping Agency. The 2012 Prohibited List. http://www.wada-ama.org/documents/world_anti-doping_ program/wadp-prohibited-list/2012/wada_prohibited_ list_2012_en.pdf. Accessed November 26, 2012.

5. Luks AM, McIntosh SE, Grissom CK, et al. Wilderness Medical Society Consensus Guidelines for the Prevention and Treatment of Acute Altitude Illness. Wilderness Environ Med. 2010;21:146-155.

\section{Has Anyone Seen My Executive Function Recently?}

\section{To the Editor:}

We enjoyed George Rodway's Wilderness Essay, ${ }^{1}$ which was intriguingly entitled "Decision making at extreme altitude: has anyone seen my executive function recently?" Obvious and potentially illuminating parallels can be drawn with cerebral function in patients undergoing locoregional carotid endarterectomy (CEA). During CEA, a crucial step during the operation is the cross-clamping of the common carotid artery. At that point, there is no flow in the ipsilateral internal carotid artery, and patients may exhibit signs of hemispheric hypoperfusion. During the operation, we try to converse with our patients to assess the adequacy of their cerebral oxygen delivery (COD). Patients often begin to deteriorate in a fairly subtle and graded fashion. Initially, they will often lose their sense of humor, and then they begin to struggle to initiate new lines of conversation. Their answers become shorter and less expansive; after that, the thought processes appear to be blunted, until finally affected patients become monosyllabic. At this point, it could be argued that they have lost their executive function, and certainly it would appear they would not to be capable of complex strategic decision making. Some patients may then go on to have mild focal neurological deficits before finally becoming profoundly obtunded. The subtle and incremental neurological degradation can usually be picked up at an early stage. Pharmacological augmentation of the blood pressure or increasing the fraction of inspired oxygen $\left(\mathrm{F}_{\mathrm{I}} \mathrm{O}_{2}\right)$ may be beneficial. If the deterioration in cerebral function is slow, that implies that there is only a modest imbalance between the regional cerebral oxygen delivery (rCOD) and regional cerebral oxygen consumption (rCOC), and any strategy that improves rCOD or decreases rCOC may reverse the deficit. ${ }^{2}$ Carotid shunt insertion is the final option.

Adequate oxygen delivery to the brain is also crucial for normal function at altitude. Oxygen carriage within the blood at altitude has conventionally been maintained a number of physiological processes (including erythropoiesis, hyperventilation, tachycardia, and increased car- 